\title{
Experimental steam turbine T10MW cold end cooling by water spraying
}

\author{
Michal Hozned $1^{1 *}$ \\ ${ }^{1}$ Doosan Skoda Power s.r.o., Experimental Research of Flow, Tylova 1/57, 301 28, Pilsen, Czech \\ Republic
}

\begin{abstract}
The paper deals with steam flow in experimental turbine T10MW, located in Škoda laboratory. The flow was examined for low or negative outputs of the turbine, i.e. for the so called last stages ventilation. The flow path of the turbine was in the Boiler Feed Pump Turbine (BFPT) version. It had all together 4 stages out of which two were last stages with the outlet to the condenser. In the area of each of the two outlets cooling nozzles were located with water for cooling the outlet steam flow and the area of last blades root cross-sections. Cooling of these areas is necessary due to the compression heat that occurs in the off design (ventilation) regimes. Various proportional amounts of cooling water and flowing steam were tested experimentally in constant pressure behind both last stages. Due to the fact that the flow path and the exhaust hood were fitted with many static pressure taps, thermometers and with the possibility of probing the temperature field along the outlet cross-section height, a number of results were achieved. These were mainly the turbine outputs, steam flows through the blades and cooling nozzles, determination of saturation limits in individual places at the outlet as well as temperature differences measured by the probe and stable thermometers. It was found out that the amount of cooling water was oversized for blade roots cooling, while the flow at the tip was cooled only minimally. The results are beneficial both in terms of further research of steam turbines in low regimes because this is how most newly produced machines are operated and for the designers of these machines.
\end{abstract}

\section{Nomenclature}

$\begin{array}{lll}\mathrm{c} & \text { velocity } & {[\mathrm{m} / \mathrm{s}]} \\ \mathrm{G} & \text { mass flow } & {[\mathrm{kg} / \mathrm{hr}]} \\ \mathrm{h} & \text { enthalpy } & {[\mathrm{kJ} / \mathrm{kg}]} \\ \mathrm{N} & \text { output } & {[\mathrm{kW}]} \\ \mathrm{p} & \text { pressure } & {[\mathrm{bar}]} \\ \mathrm{t} & \text { temperature } & {\left[{ }^{\circ} \mathrm{C}\right]} \\ \mathrm{u} & \text { circumferential velocity on mid blading diameter } & {[\mathrm{m} / \mathrm{s}]}\end{array}$

\footnotetext{
*Corresponding author: michal.hoznedl@doosan.com
} 


\section{Abbreviations \& subscripts}

$\begin{array}{ll}\text { LSB } & \text { last stage blade } \\ \text { L-0 } & 3^{\text {rd }} \text { stage } \\ \text { L-1 } & 2^{\text {nd }} \text { stage from the inlet } \\ \text { L-2 } & 1^{\text {st }} \text { stage from the inlet } \\ \text { rpm } & \text { revolutions per minute } \\ \text { sat } & \text { at saturated line } \\ \text { RB } & \text { rotor blades } \\ \text { SB } & \text { stator blades } \\ \text { ST } & \text { stage } \\ \text { cw } & \text { cooling water }\end{array}$

$\begin{array}{ll}1 & \text { left side } \\ \mathrm{m} & \text { middle } \\ \mathrm{mix} & \text { mixture } \\ \mathrm{r} & \text { blade root, right side } \\ \mathrm{s} & \text { steam } \\ \mathrm{t} & \text { blade tip, total } \\ \mathrm{x} & \text { axial direction } \\ 0 & \text { condition (plane) before stage } \\ 1 & \text { condition (plane) after stator } \\ & \text { blades of stage } \\ 2 & \text { condition (plane) after stage }\end{array}$

\section{Introduction}

The flow research in steam turbines at low regimes is performed mainly using numerical simulations of the flow $[1,2]$. In certain cases experimentally obtained results are available [3], when experiments were performed on model steam turbines. It is valuable to compare both methods, which ensures two-way data validation [4]. Due to the fact that ventilation regimes influence also the dynamic behaviour mainly of the last rotor blades, it is necessary to monitor the interaction of flow and dynamic load [5]. Similar results are rare, when experiments were performed on work (in the described case on 34 MW turbine in waste incinerator plant) [6]. Even in this case the flow parameters around the last stage are related to the amplitude of blade vibration defined by the BTT system (blade - tip - timing). It is often possible when researching low regimes in steam turbines to use the results and experience from the study of a similar phenomenon on axial compressors [7]. On these machines similar phenomena occur at first stages. Similar to turbine T10MW when measured in the BFPT version, in [8] a variable speed turbine was investigated. This paper is a significant follow-up to [9], which describes in detail research performed using a water brake (for high outputs) and a dynamometer (for low or negative outputs). The submitted paper investigates the influence of water flow through cooling nozzles located in the area of turbine last stages on the cooling of the outgoing steam flow. Similar works are unique and research is performed mainly using numerical simulations [10]. Also the phenomena related to the occurrence and movement of water films and water droplet of the liquid phase are numerically simulated $[11,12]$.

\section{Experiment description}

The experimental research on flow at the T10MW experimental steam turbine in configuration BFPT using an electric dynamometer was performed as work following experiments carried out with a water brake. The dynamometer is a device which is able to brake or actuate the turbine. It is also possible to set the regime in which the rotor or blades output is equal to zero. The dynamometer has a working speed in the range from -12 800 to $+12800 \mathrm{rpm}$. In this case the research on BFPT was carried out at nominal (design) speed of $8000 \mathrm{rpm}$. The dynamometer is limited by the braking output on the level900kW @ $8000 \mathrm{rpm}$. Thus, where it was possible, the results from the electric dynamometer were added to the results measured using the water brake. The water brake is a device for absorbing turbine output using water heated in the brake blades. The water brake was operated at a 
speed of 4000 to $5250 \mathrm{rpm}$, while the turbine output was up to $4 \mathrm{MW}$. Higher speed of the brake was not possible to reach for technical reasons. Results obtained using water brake are only supplementary for the purposes of this article.

During the measurement, the behaviour of LSB was observed at the turbine low load regime, achieved by the high backpressures or low LSB flow rates. The LSB regime falls from turbine mode to compressor mode during turbine ventilation. The medium is compressed, heated and dried. Temperature and pressure measurements in the tip area of both last stages was carried out together with the measurement of rotor output, amount of cooling water flowing through the jets and steam flowing through the flow path. Temperatures were measured at both last stage outlets using stable thermometers or temperature probe traversing. Due to the fact that both the probe and the stable thermometers were placed in axially and circumferentially different positions a spatially uneven arrangement of the flow was found.

During the evaluation a certain problem occurs due to different loads of last two stages. This difference is given by the pressure loss in the bypass channel and mainly by the different backpressure given by the obstacles in steam flow in direction to the condenser. As a result, the mass flow rate in both of LSBs (and also axial outlet velocity from LSB) was divided in ratio 50/50 from the total flow rate at the turbine inlet.

The positions of measuring points (static pressure taps and thermometers, or passages for probes) are shown in Fig. 1.

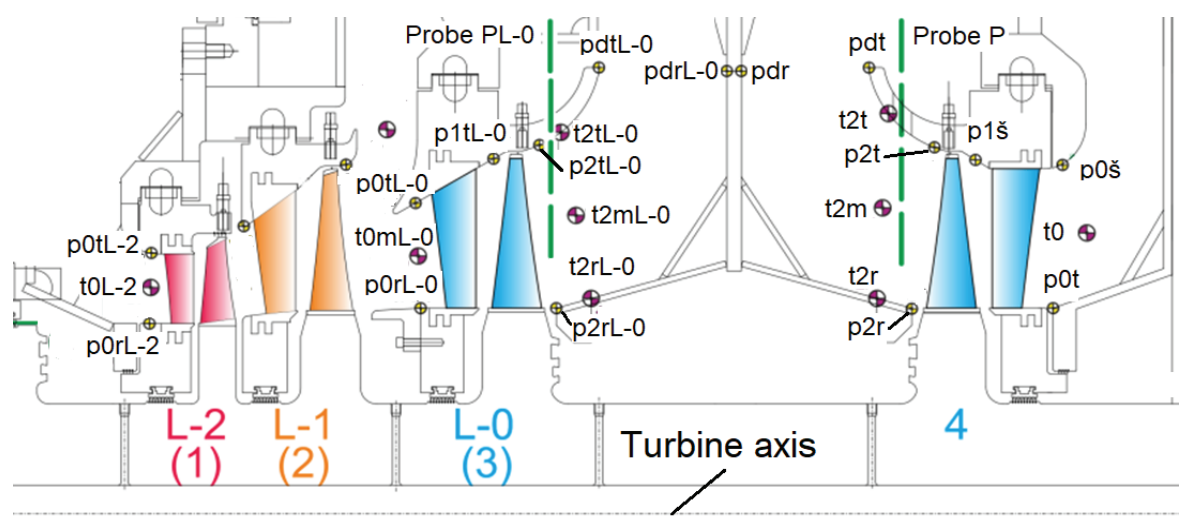

Fig. 1. Position of measuring points

At the same time Fig. 1 shows the section of the turbine. Steam enters the L-2 stage, where the inlet static pressure $\mathrm{p}_{0 \mathrm{~L}-2}$ and inlet temperature $\mathrm{t}_{0 \mathrm{~L}-2}$ are measured. After L-1 the steam flow is divided and about a half of the steam flows through six by-pass channels to the $4^{\text {th }}$ stage, while the second half flows to the L-0 stage. Behind the outlet of both stages it is possible to probe or to measure temperatures at three heights of the outlet cross section. Due to wall pressures measuring it is also possible to define the state of steam (wet or superheated) in the area of root and tip section. All measuring points are doubled, static pressure taps and thermometers are located at two circumferentially different places.

While in Fig. 1 the position of measuring points is shown schematically, in Fig. 2 the positions of measuring ends of thermometers (circles) and the probe (dashed line) are drawn in a geometrical relations to LSB. It must be added that thermometers were placed $16^{\circ}$ below the dividing plane, while the temperature probe moved $25^{\circ}$ above the dividing plane at the L- 0 stage and $15^{\circ}$ above the dividing plane at the $4^{\text {th }}$ stage. These positional differences are given by the design of passages and space constraints around the turbine. The longest direct distance between the thermometer $\mathrm{t}_{2 \mathrm{tL}-0}$ and the thermal probe position in the area of tip cross section is about $400 \mathrm{~mm}$. Due to the fact that the flow in ventilation regimes is not 
circumferentially symmetrical the steam flows rather through the lower half of the cross section and thus large temperature differences can be expected between the temperatures detected by probing and those from stable thermometers.

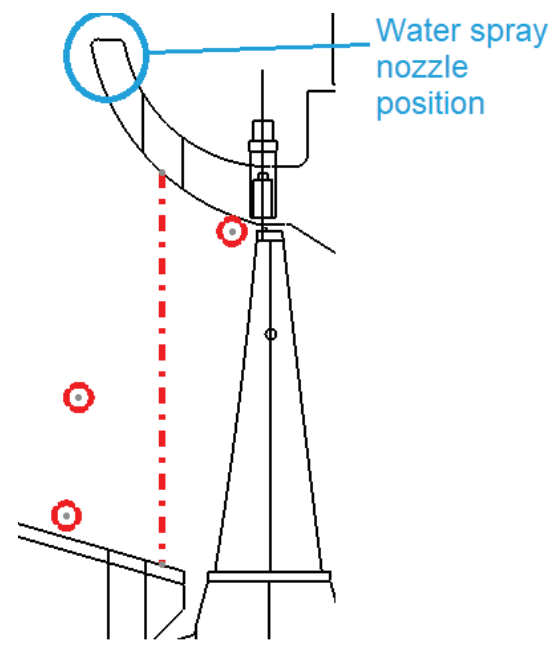

Fig. 2. Position of measuring points

Fig. 3. Water spray nozzle detail

Measurement of static pressures using static pressure taps and probes was carried out using pressure scanners NetScanner 9022 and sensors NetScanner 9401 with the range of 0-1.06 bar. The combined standard uncertainty of measurement of the static pressure at the level $2 \sigma$ under the pressure in the condenser about $5000 \mathrm{~Pa}$ is $110 \mathrm{~Pa}$. The impulse piping was blown each $120 \mathrm{~s}$ in order to clean pressure pipes from condensed water. A total of 36 pressures were measured in the flow path.

Temperatures were measured using four-wire Pt100 class A resistance thermometers and measuring card NI 9216. Uncertainty of temperature measurements is $\pm 0.3{ }^{\circ} \mathrm{C}$. In the flow path 22 temperatures were measured. The flow of cooling water and steam to the turbine was 
determined using measuring orifices. The torque was determined using a torquemeter and at the same time also an electric dynamometer with measurement uncertainty of $\pm 0.2 \%$.

In Fig. 2 the position of cooling nozzles placed at the end of the deflector and pointing in the axial direction is shown. In Fig. 3 there is a detail of the nozzle, the assumed cooling water spray cone and the indicated steam direction. The amount and velocity of water must be such as to overcome the steam flow from the rotor blades. At the same time the droplets must be small enough to evaporate before they reach the RB trailing edges. The nozzles at the outlet of the $3^{\text {rd }}$ and $4^{\text {th }}$ stage were circumferentially located after $90^{\circ}$, so behind each stage were 4 nozzles with the spray angle of $60^{\circ}$. The flow rate to both nozzles could be regulated by means of a simple ball valve. In addition to the nozzles behind both stages a third circuit was connected to cool the condenser. However, this circuit was disconnected during the described measurement. The water flow to all three circuits was measured with one orifice dimensioned for the maximum of $1000 \mathrm{~kg} / \mathrm{hr}$. Based on the manufacturer's data the maximum flow to the total of 8 nozzles was determined to be $750 \mathrm{~kg} / \mathrm{hr}$ for injected water pressure of 25 bar.

\section{Measured regimes}

A total of 13 regimes differing in rotor power were measured. This was given by the inlet pressure $\mathrm{p}_{0 \mathrm{~L}-2}$ and temperature $\mathrm{t}_{0 \mathrm{~L}-2}$ and pressure in the condenser $\mathrm{p}_{\mathrm{c}}$. The flow through the turbine which ranged between $9000 \mathrm{~kg} / \mathrm{hr}$ and $34000 \mathrm{~kg} / \mathrm{hr}$ depended on the inlet parameter. The turbine output measured by electric dynamometer after deducting mechanic losses was between $-400 \mathrm{~kW}$ (engine regime) and $650 \mathrm{~kW}$ (turbine regime). The designation and overview of individual regimes from the point of view of the condenser pressure $\mathrm{p}_{\mathrm{c}}$ is in Fig. 4 a) and from the point of view of the flow, inlet pressure and condenser pressure is in Fig. 4 b).

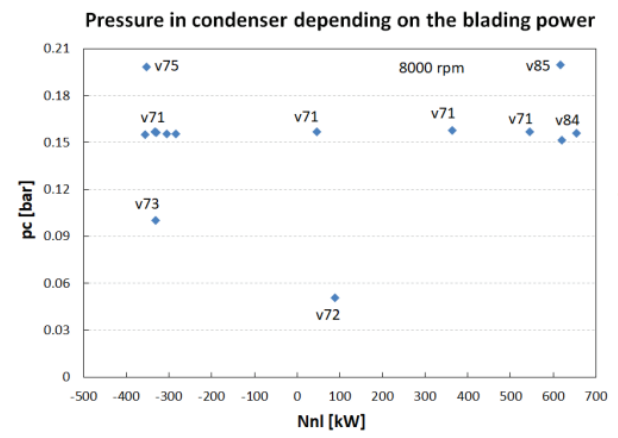

a)

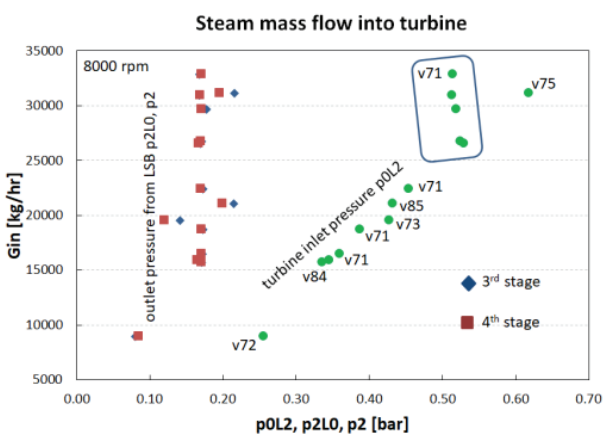

b)

Fig 4. a) Backpressure depending on the blading power; b) Steam mass flow into turbine

An overview of measured regimes including the flow through cooling nozzles related to steam flow through the last blades is shown in Tab. 1. Measurement of the influence of cooling water flow was carried out for variants v71a, b, c, d. In Tab. 2 other parameters of individual regimes are given. One of them is the ventilation coefficient $c_{2 x} / \mathrm{u}$, which indicates whether the last stage (not the whole rotor) is in ventilation, i.e. whether its output is equal to zero. Limit value of coefficient $c_{2 x} / u$ is for the given stage 0.181 , which corresponds to the outlet axial velocity $c_{2 x}=74.4 \mathrm{~m} / \mathrm{s}$. However, this figure does not say anything about the circumferential velocity that can be significant. The velocity vector can then approach the speed of sound. The value of cooling spray relative mass flow is a percentage of cooling 
water sprayed behind the stage to the steam flow through this stage provided that the steam and water are divided into both flows in the ratio of 50/50. In Tab. 1 the flow of cooling water through the circuits behind both last stages is given.

Table 1. Inlet and outlet parameters

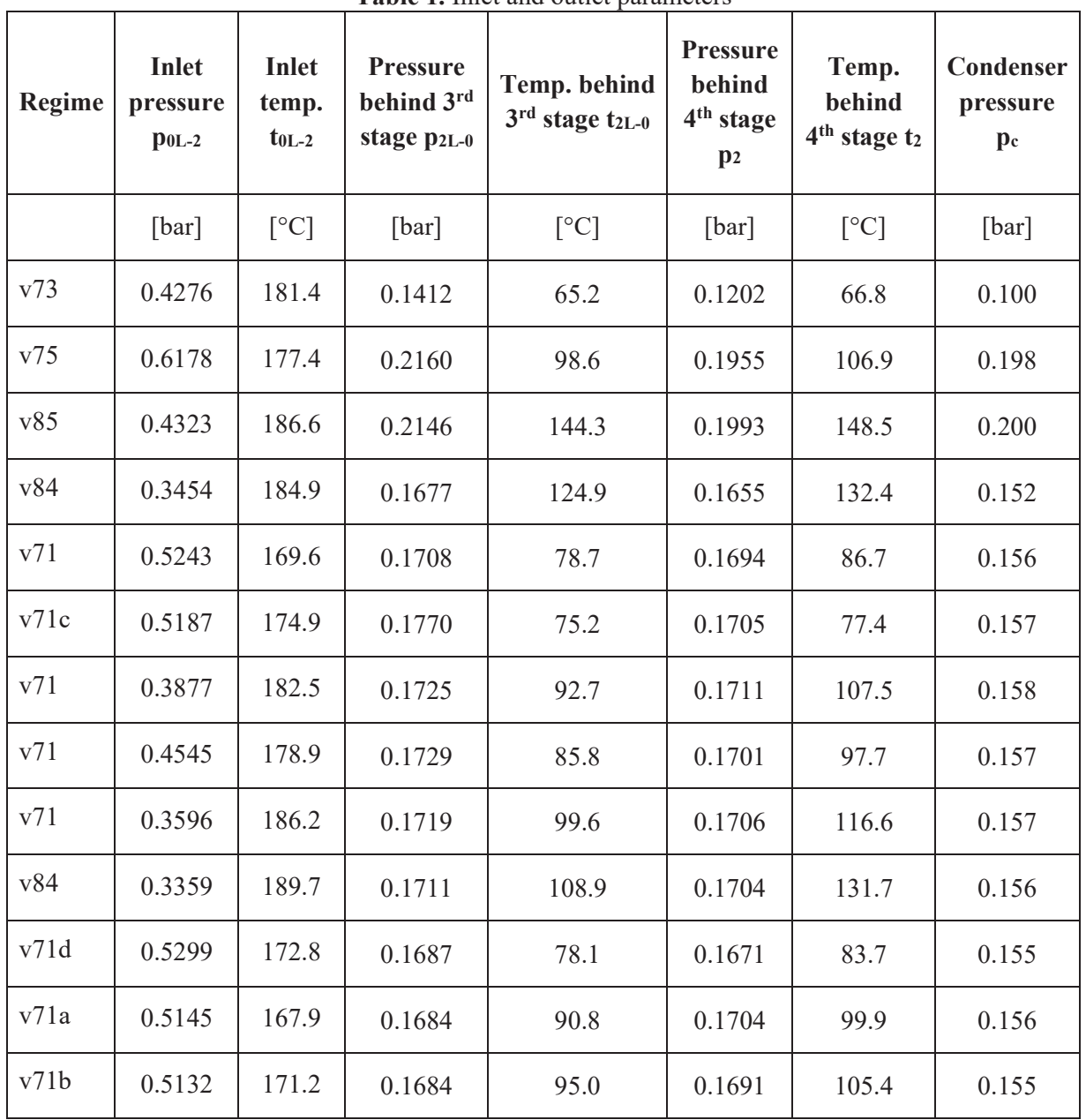


Table 2. General parameters

\begin{tabular}{|c|c|c|c|c|c|}
\hline Regime & $\begin{array}{l}\text { Inlet steam } \\
\text { mass flow } G_{s}\end{array}$ & $\begin{array}{c}\text { Spraying } \\
\text { water mass } \\
\text { flow } \mathbf{G}_{\mathrm{cw}}\end{array}$ & $\begin{array}{c}\text { Cooling spray } \\
\text { relative mass } \\
\text { flow } \mathbf{G}_{\mathrm{cw}} / \mathbf{G}_{\mathbf{s}}\end{array}$ & $\begin{array}{c}\text { Blading } \\
\text { output N }\end{array}$ & $\begin{array}{l}\text { Ventilation } \\
\text { coefficient }\end{array}$ \\
\hline & {$[\mathrm{kg} / \mathrm{hr}]$} & {$[\mathrm{kg} / \mathrm{hr}]$} & & {$[\mathrm{kW}]$} & {$[-]$} \\
\hline v73 & 26314 & 758 & \multirow{5}{*}{$2-2.8 \%$} & -331.6 & 0.091 \\
\hline v75 & 36347 & 750 & & -352.4 & 0.102 \\
\hline v85 & 30841 & 704 & & 617.4 & 0.077 \\
\hline v84 & 26403 & 701 & & 619.8 & 0.069 \\
\hline v71 & 34223 & 794 & & -330.2 & 0.100 \\
\hline v71c & 32942 & 410 & $1.24 \%$ & -333.2 & 0.107 \\
\hline v71 & 28471 & 813 & \multirow{4}{*}{$2-2.8 \%$} & 364.2 & 0.073 \\
\hline v71 & 31985 & 800 & & 45.8 & 0.085 \\
\hline v71 & 26399 & 794 & & 545.9 & 0.066 \\
\hline v84 & 26518 & 776 & & 654.8 & 0.065 \\
\hline v71d & 33501 & 810 & $2.42 \%$ & -356.9 & 0.100 \\
\hline v71a & 33282 & 45 & $0.14 \%$ & -304.6 & 0.128 \\
\hline v71b & 32517 & 172 & $0.53 \%$ & -283.9 & 0.123 \\
\hline
\end{tabular}

\section{Experiment results}

Due to different velocity of the turbine operating with a dynamometer and a water brake it is necessary to normalize the velocity by changing the flow, i.e. by the axial outlet velocity. In Fig. 4 temperatures are shown behind the $3^{\text {rd }}$ and the $4^{\text {th }}$ stage at the root, tip and in the middle of the channel length. The $\mathrm{x}$-axis shows the ventilation coefficient $\mathrm{c}_{2 \times \mathrm{L}-0} / \mathrm{u}$ for the $3^{\text {rd }}$ stage, or $c_{2 x} / u$ for the $4^{\text {th }}$ stage. Cooling using nozzles took place only for measuring with dynamometer, i.e. for $\mathrm{c}_{2 \mathrm{x}} / \mathrm{u}<0.13$ and $\mathrm{c}_{2 \mathrm{xL}-0} / \mathrm{u}<0.12$. During measuring with water brake the cooling nozzles were switched off. Despite the maximum cooling water flow in most regimes (except for regimes v71a, b, c) there was no cooling of the steam flow near the rotor blades tip and with decreasing ventilation coefficient, on the contrary, the temperature behind the tip further increased. The steam flow at the blades root and near the middle of the outlet channel was constantly cooled regardless of the ventilation coefficient value. 


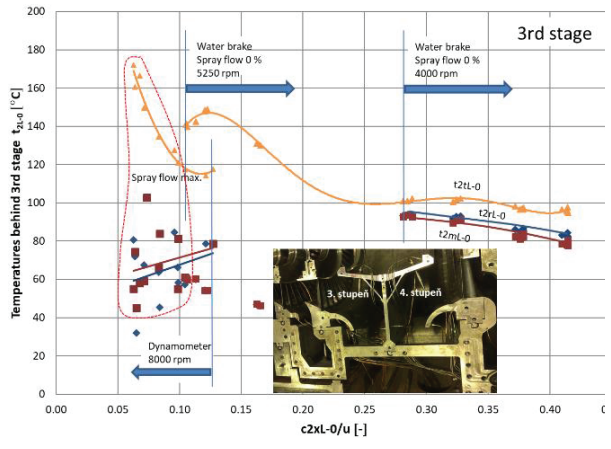

$3^{\text {rd }}$ stage)

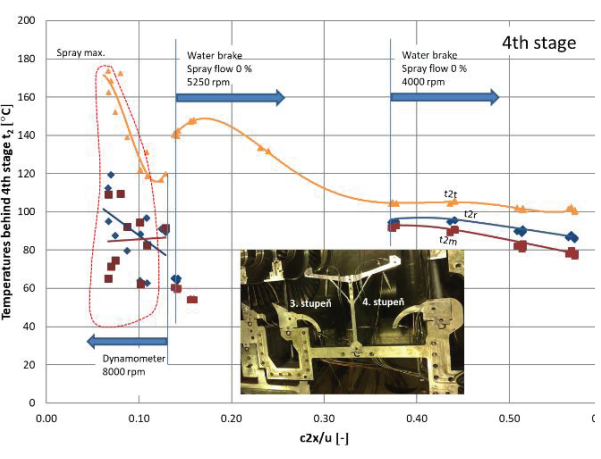

$4^{\text {th }}$ stage)

Fig. 5. Temperatures measured behind both last stages

Contours of velocity vectors in the area of both last stages and the outlet diffuser obtained using CFD calculations of flow together with the cooling water cones are shown in Fig. 6 for parameters corresponding with regime v71a. The area of high velocity near the outer limiting wall of the diffuser is evident and below there is a huge area with ventilation vortex. From the measurement results it can be concluded that water droplets sprayed from nozzles pass the area with high velocity, get to the ventilation vortex, cool the thermometers at the root and in the middle of the channel, but, at the same time, probably do not cause erosion of the $\mathrm{RB}$ trailing edges at the root.

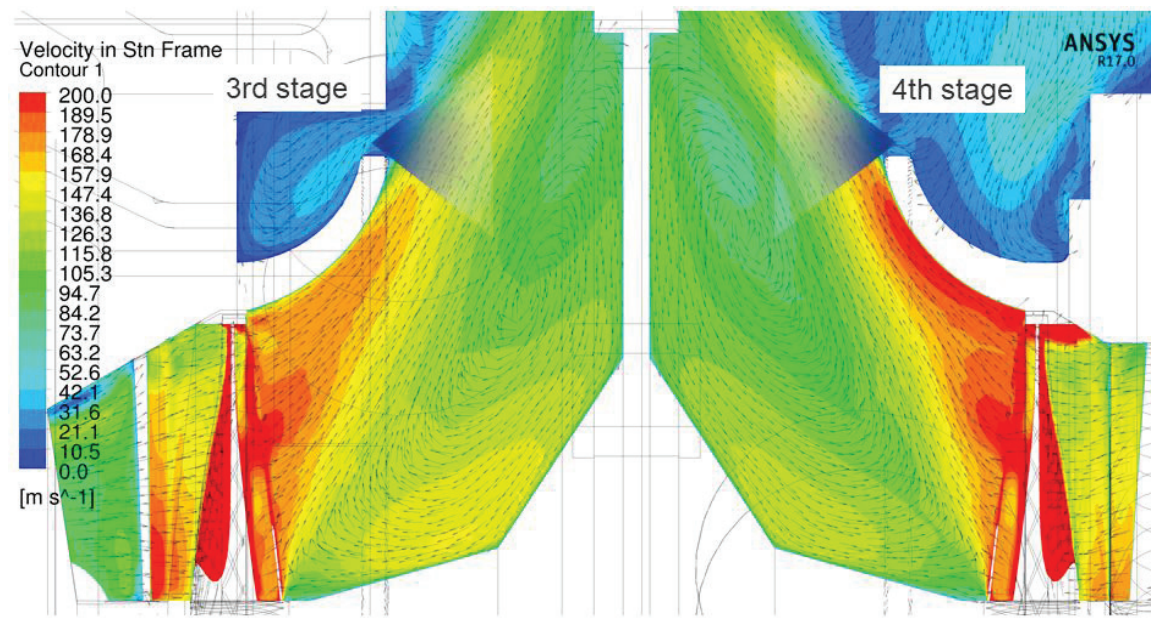

Fig 6. Velocity vector contours

The quality of steam cooling in the area of root and tip limiting wall of both last stages can be determined also from measured temperatures and temperatures at the saturation limit. These temperatures are calculated on the basis of the pressures measured by wall pressure taps. The steam can then be maximally cooled just to the saturation temperature. If the measured temperature is higher than the saturation temperature for the given pressure then water cooling is not sufficient. In Fig. 7 courses of measured temperatures and saturation temperatures are shown for both stages, for regimes measured using water brake $\left(\mathrm{c}_{2 \mathrm{x}} / \mathrm{u}\right.$ a $\mathrm{c}_{2 \times \mathrm{L}-0} / \mathrm{u}>0.13$ ) and using dynamometer. For most regimes measured with dynamometer the flow of cooling water was maximal. Nevertheless, the steam flow behind the RB tip could 
never be cooled and the temperature further increased with deteriorating low operation. Although the temperature in the root cross section area also did not reach the saturation limit, the steam was able to cool significantly. However, it is not possible to determine whether the cooling was caused by cooling water or by the influence of the ventilation vortex, see Fig. 6 .

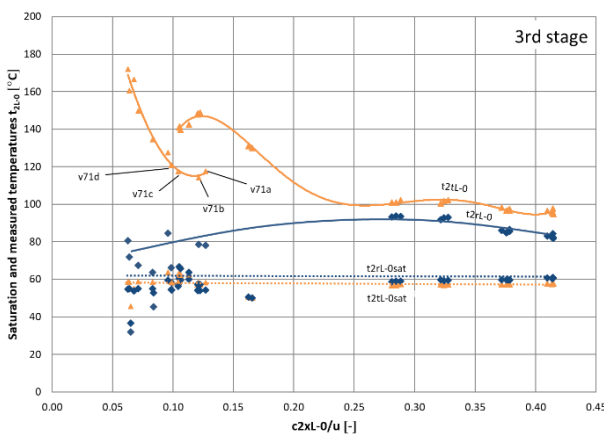

$3^{\text {rd }}$ stage)

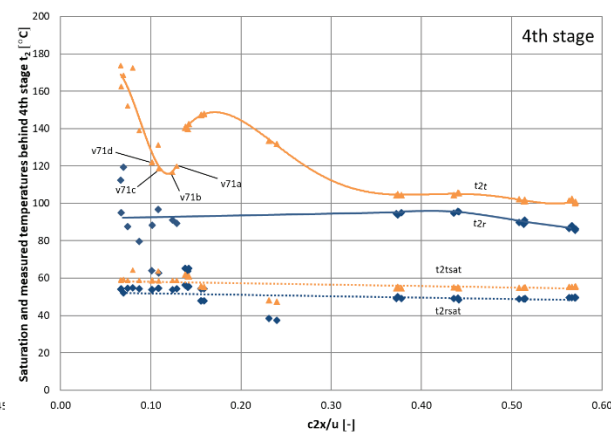

$4^{\text {th }}$ stage)

Fig. 7. Saturation and measured temperatures behind both last stages

For regimes v71a, v71b, v71c and v71d it is possible to write energy evaluation for steam, cooling water and the final mixture, here e.g. for the $4^{\text {th }}$ stage:

$$
G_{2 s L-0} \cdot h_{2 s L-0}+G_{2 c w L-0} \cdot h_{2 c w L-0}=G_{2 m i x L-0} \cdot h_{2 m i x L-0}
$$

Cooling water enthalpy $\mathrm{h}_{\mathrm{cw}}$ can be defined using the IAPWS 97 tables as a function of water pressure $\left(29\right.$ bar) and water temperature $\left(32{ }^{\circ} \mathrm{C}\right), \mathrm{h}_{2 \mathrm{cwL}-0}=136.729 \mathrm{~kJ} / \mathrm{kg}$. Enthalpy of the water and steam mixture behind the $3^{\text {rd }}$ stage blades $\mathrm{h}_{2 \text { mixL-0 }}$ can be defined from measurement using mean pressure $\mathrm{p}_{2 \mathrm{~L}-0}$ and temperature $\mathrm{t}_{2 \mathrm{~L}-0}$. Temperature $\mathrm{t}_{2 \mathrm{~L}-0}$ is determined as a mean value from temperatures $t_{2 \mathrm{rL}-0}, \mathrm{t}_{2 \mathrm{~mL}-0}$ and $\mathrm{t}_{2 \mathrm{tL}-0}$, pressure is determined as the mean value of pressures $\mathrm{p}_{2 \mathrm{rL}-0}$ and $\mathrm{p}_{2 \mathrm{tL}-0}$.

Now the enthalpy of steam behind the blades can be calculated:

$$
h_{2 \mathrm{sL}-0}=\frac{G_{2 m i x L-0} \cdot h_{2 m i x L-0}-G_{2 c w L-0} \cdot h_{2 c w L-0}}{G_{2 s L-0}}
$$

At this stage of calculation, data already exist for the calculation of theoretical steam temperature $\mathrm{t}_{2 \mathrm{SL}-0}$ for various injected amounts, but without the influence of injecting, as a function $\mathrm{t}_{2 \mathrm{SL}-0}=\mathrm{f}\left(\mathrm{p}_{2 \mathrm{~L}-0}, \mathrm{~h}_{2 \mathrm{SL}-0}\right)$. The calculated steam temperature should be the same for all 4 evaluated regimes, but in fact oscillates between 90 and $108{ }^{\circ} \mathrm{C}$. This is caused mainly by different steam flows (26 500 up to $32800 \mathrm{~kg} / \mathrm{h}$ ) and partly also by different pressures in the condenser ( 0.168 up to 0.177 bar).

In the next step it is necessary to calculate also the enthalpy of the mixture, but assuming complete evaporation of cooling water. The enthalpy of the mixture will be determined by measured pressure behind the blades and the steam dryness $\mathrm{x}=1$.

$$
\frac{G_{2 s L-0} \cdot h_{2 s L-0}+G_{2 c w L-0} \cdot h_{2 c w L-0}}{G_{2 m i x L-0}}=h_{2 m i x L-0}=f\left(p_{2 L-0}, x=1\right)
$$


Iteratively the flow rate $\mathrm{G}_{2 \mathrm{cwL}-0}$ can be determined such that the saturation temperature for pressure $\mathrm{p}_{2 \mathrm{~L}-0}$ corresponds with the saturation temperature of the mixture, given by the enthalpy $\mathrm{h}_{2 \text { mixL-0. }}$. Both temperatures must then be equal at the end of the iterative calculation. The determined flow $\mathrm{G}_{2 \mathrm{cwL}-0}$ can then be substituted to the equation (3) and the relative flow of water to the cooling nozzles can be determined. For the $3^{\text {rd }}$ stage the relative flow to reach saturation limit of steam in the whole cross section is $\mathrm{G}_{2 \mathrm{sytL}-0}=\mathrm{G}_{2 \mathrm{cwL}-0} / \mathrm{G}_{2 \mathrm{sL}-0}=2.74 \%$ and for the $4^{\text {th }}$ stage it is $\mathrm{G}_{2 \mathrm{cw}} / \mathrm{G}_{2 \mathrm{~s}}=3.43 \%$ (the steam flow through each of both last stages is $16640 \mathrm{~kg} / \mathrm{h}$ ). The temperature of steam flow in plane 2 that equals to the saturated steam temperature assuming total evaporation of water can be referred to as $t_{2 \text { mixL-0-minimal. }}$

Temperatures $t_{2 \mathrm{sL}-0}$ and $\mathrm{t}_{2 \mathrm{mixL}-0 \text {-minimal }}$ give the range in which the measured temperature $t_{2 L-0}$ should be found. This is confirmed also in Fig. 8. Also the courses of temperatures $t_{2 r L}$ $0, \mathrm{t}_{2 \mathrm{~mL}-0}$ and $\mathrm{t}_{2 \mathrm{t}-0}$ are shown in this figure. While the temperature behind the RB tip is still high, temperatures in the middle and at the root of the channel decrease and already at a relative flow rate of $1.2 \%$ for the $3^{\text {rd }}$ stage it cools to saturation temperature for a given pressure $t_{2 \mathrm{~L}-0 \mathrm{sat}}$. On the other hand, temperature at the tip never decreases due to cooling water spraying. It corresponds with the measured temperature $\mathrm{t}_{2 \mathrm{~L}-0}$ that is for relative flow $1.2 \%$ still at the minimal possible value, while for a higher value of relative flow it increases due to the fact that the steam flow behind the tip cannot be cooled by the given spray configuration. Thus, it can be said that about $50 \%$ more cooling water is sprayed to the steam flow than would be necessary to cool the mixture to the saturation temperature. The unevaporated water can cause erosion of trailing edges at the rotor blades root. Similar conclusions can be drawn also for the $4^{\text {th }}$ stage, see Fig. 8 b).
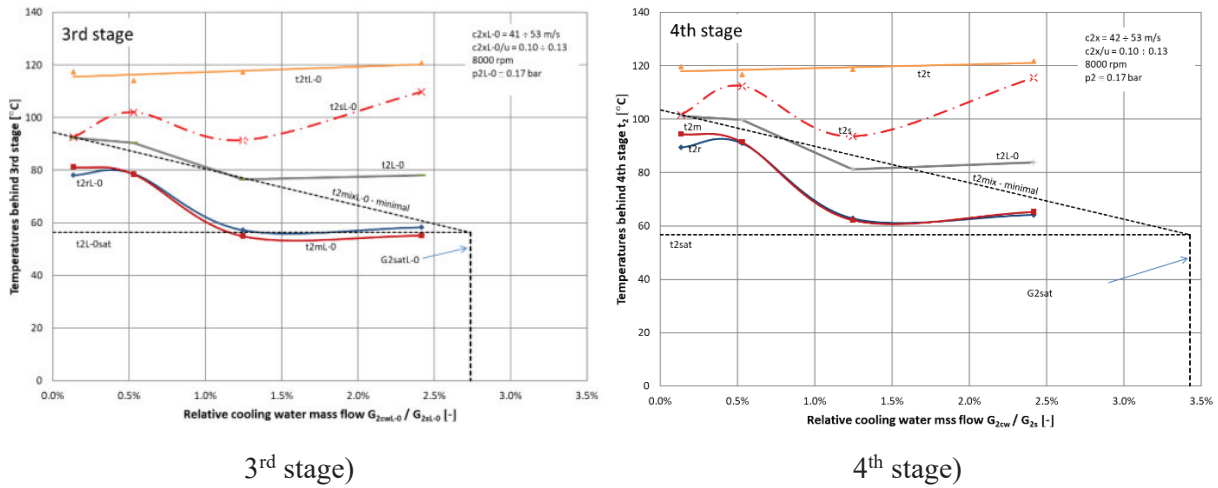

Fig. 8. Saturation and measured temperatures behind both last stages

\section{Conclusions}

Experimental research of water steam flow in the 4-stage flow path was carried out on an experimental steam turbine T10MW in BFPT design. Energy of the rotor was absorbed by water brake or by electric dynamometer. In certain operations, on the other hand, the rotor was driven by the dynamometer, and the turbine output was negative. The main emphasis in the research was placed on the outlet steam flow behaviour for nominal and mainly for ventilation regimes of the turbine. The steam flow in ventilation regimes is supplied with heat from the last stages that operate in the compressor regime. Steam at the last rotor blades outlet had to be therefore cooled by external water spray.

Measurements without the spray influence revealed that the highest steam temperature is in the area behind the rotor blade tips for both the nominal and ventilation regimes. As the steam flow through the blades decreases, the temperature behind the rotor blade tip increases 
significantly. The steam temperature at this point can reach up to $180{ }^{\circ} \mathrm{C}$, while steam temperature at the area of root and middle blade diameter remains unchained, about $100{ }^{\circ} \mathrm{C}$. The temperature of steam saturation at the root and the tip is lower than the measured temperature. The steam is superheated throughout the cross section.

In the next part of the experiments the influence of the amount of cooling water related to the steam flow through the blades was determined. Gradually, the amounts of $0,0.14,0.53$, 1.24 and $2.42 \%$ of relative cooling water mass flow related to the steam flow through the last stage were injected to the exhaust hood area. For relative flow of $1.24 \%$ and higher the outlet steam flow was cooled near the root and middle blade diameter to the saturation limit. The steam at the tip could not be cooled even at maximum flow of cooling water. Maximum water flow was designed with regard to the assumed cooling of the whole outlet cross section to the saturation limit. However, the entire cross section can never be cooled, as the cooling water droplets can never reach the fast flowing steam. Needlessly, about twice as much water is sprayed to the area near the root and middle of the blades as would be necessary to reach the saturation temperature. Unevaporated droplets can then cause erosion of trailing edges at the root of rotor blades.

The presented work was financially supported by the Technology Agency of the Czech Republic; project TK01020029 Efficiency Increasing of Turbine Wet Steam Last Stages, by National Energy Centre TN01000007 and by Technology Agency of the Czech Republic; project FW03010515 Ultra flexible operation regimes of steam turbines.

\section{References}

1. TANUMA, T. et al. Unsteady flow effects on steam turbine last stage blades at very low load operating conditions. Proc. ASME TurboExpo, 2018. GT2018-76498, https://doi.org/10.1115/GT2018-76498.

2. MAMBRO, A. et al. CFD modelling of steam turbine last stage blades at low load using multiple mixing plane approach. Proc. ASME TurboExpo, 2020. GT2020-14667, https://doi.org/10.1115/GT2020-14667.

3. Haller, B. Alleviation of rotating pressure oscillations in the last LP turbine stage during low-load conditions. Proc. ASME TurboExpo, 2016. GT2016-56088, https://doi.org/10.1115/GT2018-76498.

4. SIGG, R., HEINZ, C., CASEY, M. Numerical and experimental investigation of a lowpressure steam turbine during windage.. Proceedings of the Institution of Mechanical Engineers, Part A: Journal of Power and Energy. Volume: 223 issue: 6, page(s): 697708, https://doi.org/10.1243/09576509JPE826 .

5. SHIBUKAWA, N. et al. A Correlation Between Vibration Stresses and Flow Features of Steam Turbine Long Blades in Low Load Conditions. Proc. ASME TurboExpo 2011. GT2011-46368, https://doi.org/10.1115/GT2011-46368.

6. HOZNEDL, M. et al. Experimental and Numerical Study of Flow and Dynamics on LSB at 34 MW Steam Turbine. Proc. ASME TurboExpo, 2020. GT2020-14280, https://doi.org/10.1115/GT2020-14280.

7. GARNIER, V. H. et al. Rotating waves as a stall inception indication in axial compressors Transactions of the ASME. Vol.113, pp. 290-302, April 1991.

8. SCHUBERT, M., TUSCHE, J. Development of a Robust LP Blade Family for Variable Speed Applications. Proc. ASME TurboExpo 2018. GT2018-76539, https://doi.org/10.1115/GT2018-76539. 
9. TUPÝ, D., HOZNEDL, M. Experimental research on ventilation at T10MW experimental steam turbine. Proc. AIP Conference Proceedings 2323, 060004 (2021); https://doi.org/10.1063/5.0041416.

10. XU, $\mathrm{M}$ et al. Effect of water spray in exhaust passage of steam turbine on flow field of the last stage during windage. In: International Journal of Heat and Mass Transfer 161:120296, https://doi.org/10.1016/j.ijheatmasstransfer.2020.120296 .

11. TISCHENKO, V.A, ALEKSEEV, R.A. Numerically Simulating the Formation and Motion of Water Films and Erosion-Hazardous Droplets in Flow-Through Parts of Steam Turbines. In: Thermal Engineering, 2019, Vol 66, No. 11, pp. 830-838. https://doi.org/10.1134/S0040601519110053.

12. GRIBIN, V.G. et al. Experimental study of the features of the motion of liquid-phase particles in the interblade channel of the nozzle array of a steam turbine. In: Power Technol Eng 51, 82-88 (2017). https://doi.org/10.1007/s10749-017-0788-x 